\title{
Georientação: uma proposta de disciplina esportiva e de introdução ao mapeamento geológico
}

\author{
Alexis Rosa Nummer ${ }^{1}$, Luziane Barbosa de Souza ${ }^{2}$, Marcelo Pereira \\ Marujo ${ }^{3}$, Soraya Almeida ${ }^{1}$, Francisco José da Silva ${ }^{1}$, Rafael Sá dos Reis ${ }^{4}$ \\ 1 Depto. de Geociências, Instituto de Agronomia da Univ. Federal Rural \\ do Rio de Janeiro. \\ 2 geóloga de exploração da Bendigo Mining Limited, Austrália \\ 3 professor universitário. Comando da Marinha, Rio de Janeiro \\ marcelo.orientador@uol.com. \\ 4 bolsista de Iniciação Científica do Depto. de Geociências, Instituto de \\ Agronomia da Univ. Federal Rural do Rio de Janeiro.
}

\begin{abstract}
RESUMO A Georientação é uma nova proposta de disciplina acadêmica e esportiva para Cursos de Graduação em Geologia, na qual o aluno executa uma atividade prática de aprendizado classificada como um ensino interativo geoambiental e esportivo. A Georientação tem sua origem no esporte de Orientação que permite ao praticante visitar pontos marcados no terreno, que são denominados de "Pontos de controle", com o auxílio apenas de um mapa e uma "bússola de georientação". Esta atividade utiliza a determinação e localização da ocorrência de afloramentos com litologias e/ou estruturas de fácil visualização que deverão ser plotados em mapas de orientação, ao longo de percurso previamente estabelecido e com tempo avaliado. A aplicação desta atividade proporciona um melhor desempenho em mapeamento geológico; ajuda no desenvolvimento do senso de orientação e raciocínio geológico do aluno, e permite ao mesmo, aprender técnicas para se locomover com segurança em locais desconhecidos.
\end{abstract}

PALAVRAS-CHAVE georientação, ensino de geociências, orientação, mapeamento geológico, cartografia geológica.

\begin{abstract}
Georienteering: combining geological mapping learning and sporting skills. Georienteering is a new academic proposal for Geology Graduation Courses, where the geology student executes a practical activity that is classified as interactive learning of geoenvironmental and sport education The Georienteering is based on the sport of Orienteering sport where the practitioners to reach to "points" marked in the land, called "control points ", assisted by a map and a georienteering compass. This activity uses to determine the occurrence and location of outcrops with lithologies and/or structures for easy viewing to be plotted on orientation map, along predetermined route and estimated time. It uses geologic data from the field and as a result it helps to provide a better performance in activities of geologic mapping, to improve the sense of orientation and geologic reasoning and to acquire the techniques for walking safely at unknown places.
\end{abstract}

KEYWORDS georienteering, Geoscience education, orienteering, geological mapping, geological cartography. 


\section{Introdução e contexto}

Este trabalho tem como objetivo principal apresentar a nova disciplina Georientação modificada e adaptada a partir da prática esportiva denominada Orientação (Orienteering). Adicionalmente pretende-se discutir sua aplicação como atividade didático-pedagógica nos Cursos de Geologia e Geografia do Ensino Superior de Geociências no país. Esta disciplina cria ferramentas de trabalho que melhoram o desempenho do aluno praticante (georientista) na atuação de atividades de cartografia geológica e de geologia de campo, visto que nesta abordagem, as atividades de campo são consideradas elementos "essenciais" ao aprendizado e fixação do conhecimento adquirido em sala de aula.

O trabalho de recuperação e aprimoramento do nível e qualidade do ensino em geral deve ser abordado individualmente pelos professores de ensino do terceiro grau, mais especificamente geologia e geografia, de acordo com cada particularidade regional destas atividades. As diferentes escolas de Geologia e Geografia devem, necessariamente, se comprometer em implementar alternativas pedagógicas que possam ser aplicadas pelos professores e que envolvam a incorporação de mecanismos essencialmente motivadores, com forte apelo de interação ambiental, e que contribuam efetivamente para uma melhor qualidade de ensino.

A disciplina Georientação, aqui proposta, foi recentemente aprovada pela Câmara de Graduação da Universidade Federal Rural do Rio de Janeiro e implantada como disciplina optativa no atual Currículo Acadêmico do Curso de Graduação em Geologia e Geografia do Departamento de Geociências, e divulgada no XXXLVIII Congresso Brasileiro de Geologia (Souza et al. 2006).

\section{Breve histórico da Orientação}

A palavra Orientação é originada da palavra oriente que significa direção do sol nascente (Friedman 2003). Desde tempos imemoriais, observadores mais atentos perceberam que o sol nascia de um lado do céu, oriente, e se punha mais ou menos no lado oposto, ocidente. A necessidade de caçar ou buscar alimentos longe de sua habitação fez com que o homem desenvolvesse estratégias que possibilitassem o seu retorno por detalhes marcantes do terreno. Ao observar o movimento do sol e das estrelas, pôde determinar os pontos cardeais - norte, sul, leste, oeste e a determinar as posições ou direções em relação aos pontos cardeais (Friedman 2003).

Como desporto, a Orientação surgiu em 1850, na Escandinávia, como atividade de treinamento para o deslocamento em guerra, e logo se transformou em meio de entretenimento para as tropas. Pouco depois o "jogo" já havia se espalhado; clubes foram criados e competições foram organizadas sob as mais diversas formas e objetivos (Palmer \& Martland 1989).

Em 1912, o Major Ernst Killander introduziu a Orientação no programa da Federação Sueca de Atletismo. Em 1919, tem lugar a primeira competição oficial de Orientação, numa prova de $12 \mathrm{~km}$ e apenas três "Pontos de Controle".

Certo tempo depois, em 1961 é criada a IOF, International Orienteering Federation, e em 1966, realiza-se o primeiro campeonato mundial. Em 1977 a Orientação (pedestre) é reconhecida pelo COI, Comitê Olímpico Internacional. Como resultado deste crescimento, em 2000, cinquenta e seis países fazem parte da IOF, inclusive o Brasil.

No Brasil, a Orientação teve inicio no meio militar nos anos 1970. Em 1983 e 1992 o Brasil é sede de Campeonatos Mundiais. Como todo desporto novo, a Orientação desenvolve-se a partir da dedicação dos praticantes e da iniciativa pioneira de alguns. Em 11 de janeiro de 1999, na cidade de Guarapuava, PR, com a presença de Higino Esteves, membro do conselho da IOF, foi fundada a Confederação Brasileira de Orientação (CBO, URL: http://www.cbo.org.br), órgão máximo da Orientação no Brasil, que agrega as Federações Estaduais e conta com inúmeros projetos para desenvolvimento do esporte.

Na vida moderna, o desporto Orientação ajuda no desenvolvimento das capacidades e inteligências múltiplas a fim de escolhermos nossos deslocamentos corretos e mais racionais, organizarmos os espaços, fugirmos de congestionamentos, decidirmos os melhores e menores percursos. Esta atividade tem desempenhado papel tão importante como aprender a ler, escrever e contar, pois é um sistema de comunicação que utiliza a linguagem cartográfica (Carvalho 1985). Como desporto, a orientação é considerada atividade para todos, pois possibilita a participação de pessoas de qualquer idade, sexo ou capacidade física, inclusive promovendo uma atividade estimulante para portadores de necessidades especiais (Mendonça 1987a). 
Entre trilhas, charcos, matas, cachoeiras e rios, crianças, jovens e adultos em atividade física e mental, trabalham o equilíbrio espacial e emocional em busca da saúde, lazer e prazer. Esses tópicos são considerados a essência da Orientação, na qual o participante escolhe sua própria rota levando em consideração as facilidades e dificuldades existentes entre as várias rotas possíveis (Confederação Brasileira de Orientação 1999).

\section{A Orientação e suas vertentes}

Face à abrangência do desporto, a $\mathrm{CBO}$, ao definir sua doutrina de trabalho, o dividiu em quatro vertentes mestras: competitiva, ambiental, pedagógica e turística.

A vertente pedagógica aqui enfocada refere-se à orientação como um dos meios para o desenvolvimento do ensino básico e profissionalizante dos cursos de Geologia e Geografia, enquanto a vertente competitiva aborda a Orientação como desporto eminentemente de competição. A vertente de lazer considera a Orientação como enriquecimento dos momentos de lazer e contato com a natureza, e a Ambiental como apoio às ações de educação ambiental, por meio de regulamentos e disposições e da conscientização dos praticantes para a valorização do meio ambiente.

No caso específico da vertente pedagógica, abordada neste trabalho, salienta-se que é aplicada como disciplina optativa introdutória, sem pré-requisitos, dos cursos de Geologia e Geografia, correspondendo ao conjunto de ações que visam colocar o desporto Orientação a serviço do aluno calouro para desenvolvimento de visualização de feições geológicas, espacialização do terreno e senso de orientação em atividades de campo.

As disciplinas de Orientação são definidas a partir do meio de locomoção utilizado para o percurso realizado, como por exemplo, correndo ou andando, usando bicicleta ou até mesmo no caso de portadores de necessidades especiais. Apesar de não ser reconhecida pela IOF como disciplina específica, a Orientação em Montanha associa a orientação à prática do montanhismo e foi aplicada neste trabalho.

Associada à Educação Física Escolar, a Orientação é um meio excelente de desenvolvimento cognitivo, psicomotor, afetivo e possibilita o trabalho inter e multidisciplinar. Tem enfoque lúdico, na linha do "aprender jogando e fazendo" onde o aluno constrói seu conhecimento a partir das situações propostas, do manuseio dos materiais e da interação com o meio.

A Orientação, pelas suas características, insere-se no âmbito das atividades com valor social, tendo principal enfoque a educação ambiental, onde promove a vida em todas as suas dimensões através da interação entre seus participantes e com o meio ambiente.

\section{Objetivos}

Este artigo tem o objetivo de contribuir para a iniciação de alunos em atividades de campo nas áreas geológica e geográfica como forma de aperfeiçoar o "senso" de orientação e o raciocínio nestas áreas. Pretende também, dar suporte e orientar professores e profissionais de ensino de Geociências na elaboração e aplicação da disciplina de georientação em suas atividades.

Os materiais e métodos necessários para a aplicação da atividade prática de ensino de Georientação são extremamente simples e de fácil incorporação. $\mathrm{O}$ aspecto fundamental a ser considerado refere-se à área de aplicação desta atividade que, necessariamente, deverá expor uma pequena gama de afloramentos de rochas de fácil visualização e compreensão pelos praticantes da georientação, aqui denominados de georientistas, adquira os conhecimentos sobre as simbologias topográficas básicas do mapa, identificação "simples" de rochas e estruturas de fácil visualização, através da consulta da legenda nele inserida.

$\mathrm{Na}$ aplicação em atividades geológicas se devem incorporar convenções relacionadas a estruturas tectônicas como: planos (foliações), linhas (lineações) e superfícies dobradas (dobras); e/ou diferentes tipos de rochas (sedimentares, ígneas ou metamórficas) com suas feições características referentes à cor, tamanho de grãos, variações de texturas etc. Sempre que ocorrer uma mudança no tipo de rocha e/ou estrutura deverá ser indicado no mapa utilizado, deverá ser realizado uma recapitulação desta fase, chamando atenção para as diferenças existentes na simbologia utilizada em cada mapa. A simbologia topográfica é extremamente importante e deverá ser considerada também, tanto para o uso devido em trabalho de campo geológico como o geográfico.

Outro aspecto fundamental a ser considerado refere-se à área de aplicaşão desta atividade que, 
necessariamente, deverá expor uma pequena gama de afloramentos de rochas de fácil visualização e compreensão pelos georientistas.

A seguir são descritos os materiais necessários e a identificação da mais adequada proposta da atividade adaptada do desporto original de Orientação.

\section{Materiais e métodos}

\section{Materiais}

\section{Bússola}

Existem atualmente modelos de bússolas para várias aplicações: navegação marítima, navegação aérea e navegação terrestre, geologia, topografia, mergulho etc. Para cada aplicação, existe uma grande quantidade de modelos disponíveis. Neste trabalho será enfatizada apenas a bússola de georientação.

No comércio existe um modelo de bússola Brunton híbrida que pode ser usada tanto na prática da atividades de orientação, quanto para trabalhos geológicos, e deste modo pode ser considerado um equipamento que reúne sistemas de medidas angulares: um no plano horizontal, a agulha magnética, e outro no plano vertical, o clinômetro, objetivando estabelecer a disposição espacial de planos e/ ou linhas geológicas. A bússola também pode servir como ferramenta de localização em campo e trabalhos topográficos expeditos com a determinação de rumos e gradientes.

Por intermédio de agulha imantada que se alinha segundo o fluxo do campo magnético terrestre e que gira livremente no plano horizontal, a bússola permite estabelecer a orientação de uma dada direção ou rumo em relação ao norte magnético; a direção pode ser de uma atitude de foliação, falha ou lineação - aplicada à Geologia Estrutural - ou apenas definir, por exemplo, um rumo de caminhamento no campo.

Normalmente o limbo em que se mede o ângulo do norte magnético tem os quadrantes W e E invertidos e pode ser girado para compensar a declinação magnética local na data dos trabalhos, obtendo-se assim, medidas da direção e rumo verdadeiros diretamente sem a necessidade de se realizar cálculos.

A grande diferença entre uma bússola de geólogo e a de orientação é que ocorre a incorporação de uma base móvel para correção da declinação magnética e um clinômetro que permite medir de forma expedita gradientes topográficos, mergulhos de camadas e planos de falhas, orientação espacial de linhas de charneira, lineações mineralógicas, mergulho verdadeiro etc. Essas bússolas permitem medir também os gradientes topográficos que representam a inclinação de uma encosta ou de um rio, que podem ser medidos seja em percentagem (diferença de altitude por distância total projetada em plano horizontal), em valores negativos (encosta ou rio abaixo) ou positivos (encosta ou rio acima).

\section{Mapa de georientação}

O mapa de georientação é modificado a partir do mapa normalmente utilizado na Orientação Pedestre (Fig. 1), no qual a partida é assinalada por um triângulo de $6 \mathrm{~mm}$ de lado; Pontos de Controle (PC) por círculos numerados de $5 \mathrm{~mm}$ de diâmetro,

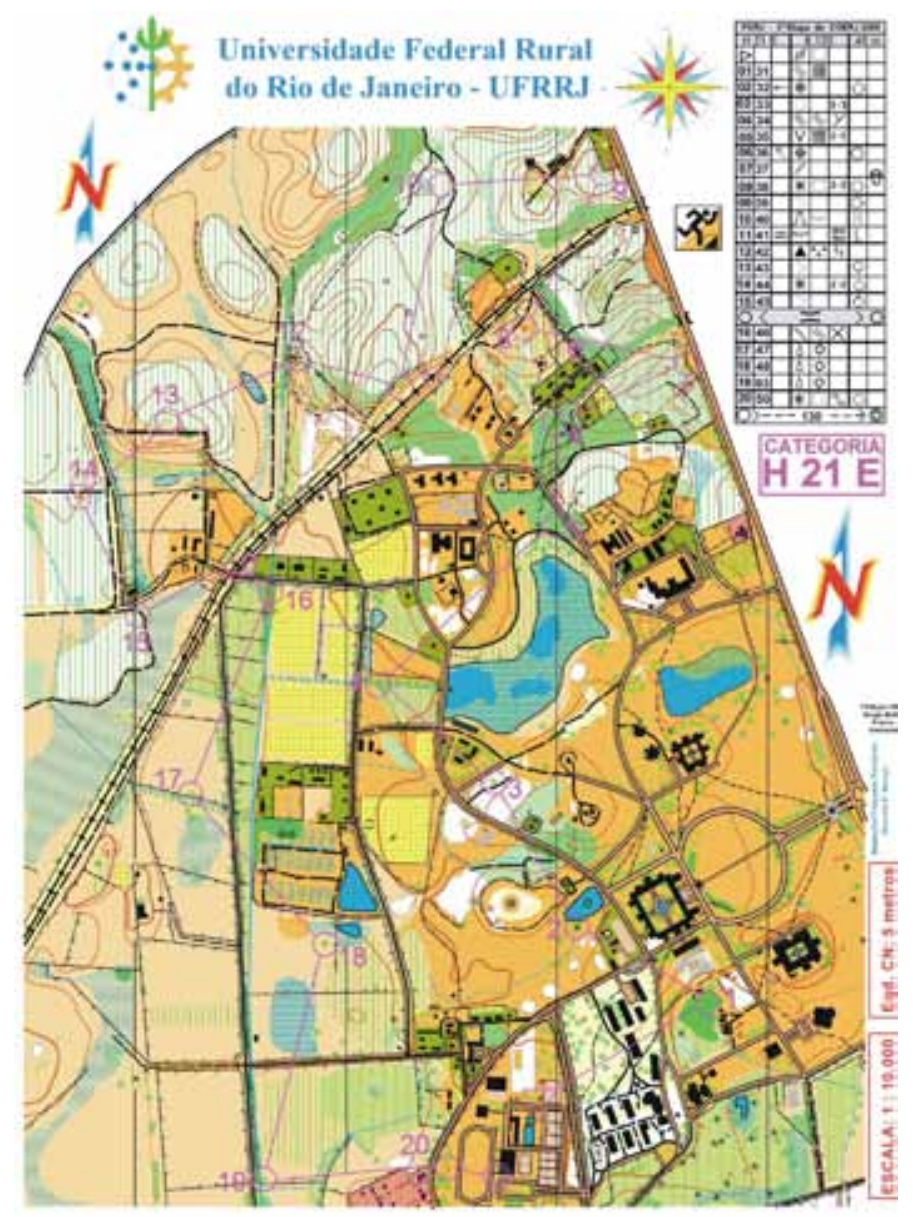

Figura 1. Mapa de orientação em que o triângulo representa a partida, os círculos numerados representam os pontos de controle e os dois círculos concêntricos representam a chegada 
e a chegada por dois círculos concêntricos de 5 e $7 \mathrm{~mm}$. Os PCs são unidos segundo a sua ordem por traços que não intersectam os círculos, sendo normalmente dispostos de forma circular de modo a evitar que os concorrentes obtenham vantagem caso alterem a ordem de percurso dos pontos de controle. Os pontos são materializados no terreno pela ocorrência de afloramentos facilmente identificáveis pelos georientistas, que exibem prismas triangulares de cor laranja e branca com $30 \mathrm{~cm}$ de lado, denominados balizas, aos quais se associam um picotador que comprova a passagem do georientista pelo ponto de controle, e um código de identificação formado por dois dígitos.

O georientista, ao encontrar um ponto de controle, utiliza o alicate (picotador) para perfurar o cartão de controle no quadrado correspondente. Isto permite aos organizadores verificarem se foram visitados os pontos de controle corretos.

As escalas adequadas do mapa de georientação variam entre 1:10.000 a 1:5.000. São mapas detalhados que representam elementos característicos do terreno como árvores, pontes, postes, trilhas, construções, matas, valas, campos, charcos, lagos, rios, riachos, locais de corrida livre (mata aberta) etc., além da indicação dos afloramentos com texturas e/ou estruturas específicas, caso específico para o georientista do curso de geologia.

\section{Método de georientação como atividade física e de ensino}

A Georientação como atividade física realiza-se de forma espontânea sempre que alguém se desloca em terreno desconhecido ou parte a procura de algum lugar especial seguindo indicações que podem ser instruções verbais, endereços ou croquis mais ou menos elaborados (Hasselstrand 1987).

A aprendizagem das técnicas de georientação, além de aprimorar as habilidades já desenvolvidas, acrescenta maior segurança e prazer às atividades de lazer ou ensino de geociências junto à natureza. Podem e devem ser associadas à pratica do campismo, trekking, mapeamentos geológicos de campo e qualquer atividade que envolva deslocamento em meio natural (Lourtie 1967).

Pode-se considerar que todas as atividades em que se recorre à utilização de um mapa, ou em que pretendemos fazer uma opção sobre o melhor trajeto a realizar entre dois locais, é orientação
(CBO 1999).

No entanto, como modalidade de ensino define-se georientação como sendo uma atividade na qual o praticante tenta realizar, no menor tempo possível, um percurso, previamente definido e marcado num mapa, tendo que percorrer, pela ordem definida no mapa, ou não, um conjunto variável de pontos de interesse geológico ou geográfico, denominados de "Ponto de Controle - PC". Estes PCs estão materializados no terreno por balizas, e pequenos alicates de plástico, que o georientista usa para comprovar que esteve nos pontos de controle, através do preenchimento de um cartão de controle (Fig. 2), que recebe na partida da atividade (site oficial da Federação de Orientação do Estado do Rio de Janeiro - FORJ).

Os cartões de controle podem ter diversos formatos, mas todos incluem quadrados numerados para a picotagem nos sucessivos pontos de controle, assim como espaços para o nome do participante, $\mathrm{o}$ percurso, o escalão, as horas de partida, e de chegada, e o tempo transcorrido para executar o percurso.

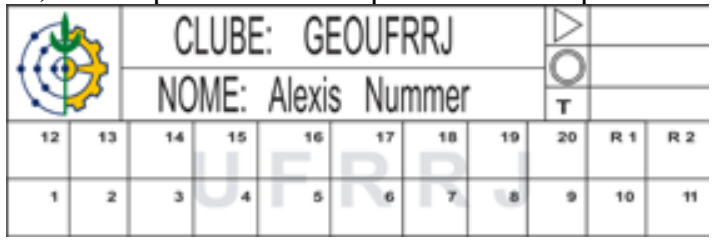

Figura 2. Cartão de Controle - quando encontra um ponto de controle, o georientista utiliza o alicate aí existente para perfurar o cartão de controle no quadrado correspondente. Isto permite aos organizadores verificar se foram visitados os pontos de controle na ordem correta. Por vezes um praticante perfura o quadrado errado do cartão. Se isto acontecer, o procedimento correto será perfurar um dos quadrados de reserva R1, R2 ou R3 (no exemplo correspondem aos quadrados 22, 23 e 24). Na chegada deverá declarar que números foram trocados

\section{Tipos de percursos de orientação}

Os tipos de percursos tradicionais de orientação podem ser: permanentes ou não, com pontuação, em linha, ida e volta denominado do tipo norueguês, e possuem aspectos positivos e negativos na sua aplicação específica. Neste tipo de organização o percurso não está previamente marcado no mapa. Assim, ao realizar este tipo de percurso, na partida temos um mapa onde está marcado o triângulo da partida e o primeiro ponto de controle, que devemos copiar para o nosso mapa que nos foi entregue em branco. À medida que se realiza o percurso, 


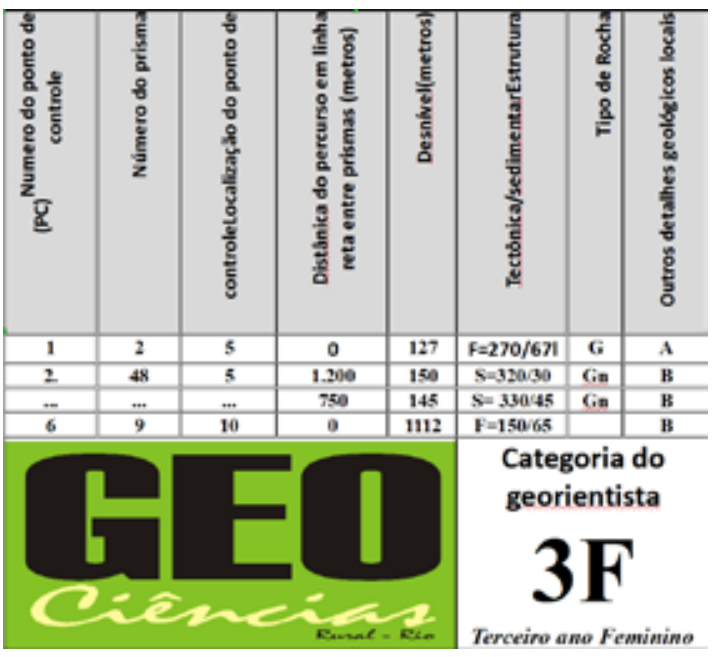

Tabela 1. Pontuação SCORE 100, na qual a primeira coluna representa o número do ponto marcado no mapa, a segunda coluna representa o código do prisma referente ao ponto marcado no terreno (afloramento) e a terceira coluna representa as respectivas pontuações de cada ponto de controle

vamos obtendo informações contidas nos sucessivos PCs para onde nos devemos dirigir.

A aplicação dos diferentes tipos de percursos dependerá da existência de acessos permanentes nas escolas, universidades ou nos espaços verdes circundantes com afloramentos adequados (parques, pequenos bosques, pedreiras etc.) abordados na Orientação tradicional a nível curricular ou mesmo extracurricular. No Percurso com pontuação são marcados mapas com a partida, a chegada e vários pontos de controle ou afloramentos, não sendo indicada a ordem de realização destes pontos, sendo que se associa a cada ponto, uma pontuação em função do grau de dificuldade. Normalmente é atribuído um tempo máximo para a realização da prova tendo como objetivo principal a passagem em maior número de pontos no tempo determinado. $\mathrm{Na}$ variante Score 100 (Tabela 1) o objetivo é realizar cem pontos.

No percurso em linha, é marcado no mapa, por meio de setas e linhas, o percurso exato que o georientista deve realizar, não sendo indicada a localização dos pontos de controle. No terreno são colocados os pontos de controle em elementos característicos por onde passa o percurso previamente definido. Durante a realização do percurso o georientista deve descobrir os pontos de controle e assinalá-los no mapa.

Para a georientação o percurso mais adequado combina dois ou mais percursos realizados consecutivamente por equipes, sendo a partida de todos os concorrentes simultânea e a totalidade dos per- cursos igual para todas as equipes. Cabe frisar que os diferentes participantes de cada grupo realizam percursos diferentes durante a atividade.

No percurso de ida e volta (ou vela de moinho) ocorre uma situação de fácil organização na qual os georientistas realizam o percurso a partir de um ponto central, onde retornam ao ponto inicial após a marcação de cada ponto de controle.

Em situações específicas com georientistas de diferentes níveis, pode-se marcar no mesmo percurso dois pontos facilmente acessíveis e dois mais difíceis como, por exemplo, alunos de nível mais avançado realizam a totalidade do percurso e os outros apenas uma parte.

"Na marcação dos mapas de georientação assinalam-se dois ou mais círculos para cada ponto de controle (1a, 1b; 2a, 2b; etc...). Em cada ponto de controle é colocado um cartaz com uma questão e várias respostas. Cada resposta à questão corresponde a um dos círculos assinalados no mapa, que dependendo da resposta, os georientistas dirigem-se para um dos locais assinalados. Se os praticantes responderem corretamente, encontram o ponto de controle seguinte, se não, terão de voltar ao ponto anterior e responder corretamente" (Baltazar 1998).

\section{Apresentação de dados}

A Georientação aqui proposta foi idealizada inicialmente com a preocupação de ser atividade que permitisse ensinar ao praticante, que neste caso específico é um estudante calouro no Curso de Geologia ou Geografia, a se localizar no campo e atuar com o raciocínio espacial utilizando mapa, bússola de georientação para medir as estruturas e símbolos geológico-topográficos. Para obtenção de resultados mais efetivos é necessário realizar aula pratica de bússola condicionado principalmente as estruturas que serão observadas nesta atividade.

O caráter único da Georientação consiste em encontrar e seguir o melhor itinerário, em terreno desconhecido, utilizando dados geológicos ou cartográficos de campo contidos no mapa, que proporcionam um melhor desempenho em atividades de mapeamento, auxilia no senso de orientação do aluno, raciocínio geológico e permite aprender técnicas para se locomover com segurança em locais desconhecidos.

Esta modalidade de ensino exige fundamentalmente: boa capacidade de orientação espacial e 
leitura do mapa, avaliação de opções de itinerário, utilização da bússola de georientação, concentração sob stress, rapidez na tomada de decisão, pois será considerado o caráter temporal e deslocamento em terreno acidentado.

Os conceitos geológicos e cartográficos aplicados à georientação são transmitidos em atividades teóricas e práticas preparatórias que incluem: aulas de instruções diversas e divulgação de conceitos e regras, que neste trabalho foram extraidos e adaptados de $h t t p: / / w w w . f p o . p t / m a n u a i s / d o c a p o i o p r o f s$. doc para a georientação. Estes conceitos e regras gerais são organizados em atividades em sala de aula e de campo próximos ou no local que será aplicada a atividade, com duração total de dois dias (geralmente em fim-de-semana) que serão considerados a seguir:

\section{Atividades expositivas em sala de aula}

1. Estudo da sinalética especifica da Orientação aborda uma grande gama de sinais gráficos convencionais que permitem ao georientista descrever pontos ou ocorrências de elementos característico da paisagem e determinar a situação espacial dos pontos de controle. Este processo traduz a dialética verbal para uma dialética gráfica. Nesta etapa o georientista estuda a sinalética da IOF (International Orienteering Federation) que usualmente se utiliza no cartão de sinalética que acompanha os mapas de provas de Orientação.

2. Noção de Distâncias e Escalas - onde o georientista deverá aferir o seu passo em diferentes situações de velocidade.

3. Elementos cartográficos gerais - envolvem todos os componentes de mapas topográficos e de orientação, com suas semelhanças e diferenças, convenções e legendas, talões diversos, sistemas geográficos e de georreferenciamento, converções de escalas etc.

4. Aula expositiva de elementos estruturais como foliações, lineações, falhas/fraturas e dobras; diferentes tipos de rochas sedimentares, igneas e metamórficas (amostras de mão) para o curso de geologia, e elementos cartográficos (diferentes tipos de mapas e escalas) para o curso de geografia.

\section{Atividades preparatórias de campo}

A atividade preparatória de campo deverá ser conduzida por meio de, no mínimo, uma aula teste de aproximadamente um dia (8 horas) levando em consideração os temas abordados em sala de aula, assim organizada:

1. Realização de pequenos atalhos - os alunos realizam pequenos atalhos (até $100 \mathrm{~m}$ ), atravessando áreas abertas ou com boa visibilidade.

2. Atividade em grupos com um responsável (professor, instrutor, aluno de nível mais elevado) que realiza pequeno percurso aproveitando os elementos naturais do terreno para realizar pequenos atalhos. O georientista verifica no mapa o percurso realizado e confere com a paisagem observada. Ao final do atalho escolhido o monitor da equipe questiona sobre o trajeto escolhido e explica o porquê da opção executada.

3. Execução de um percurso a ser realizado por atalhos, com pontos de controle colocados de maneira bem visível. Estes atalhos devem ser executados na direcção de elementos característicos importantes (estradas, caminhos, áreas abertas, linhas de alta tensão etc.), que posicionados perpendicularmente à direção do deslocamento.

4. Divisão da classe em pequenos grupos de 3 ou 4 integrantes - escolher uma zona com referências lineares perpendiculares à direção Norte-Sul; marcar no mapa o percurso a ser realizado, referenciando os respectivos atalhos de até $100 \mathrm{~m}$ nas direções Norte e Sul. Nesta opção o georientista utiliza a bússola, bastando para tal, seguir a direção (Norte ou Sul) indicada pela agulha magnética. Após terminar o percurso é realizádo no sentido contrário.

5. Noção de relevo e sua planificação - o conhecimento do relevo e a sua correta leitura no mapa são importantes e constitui um elemento característico de grande fidelidade que permite uma "navegação" com grande precisão e um correto equilíbrio de esforço a ser dispendido através da opção escolhida nos diferentes trajetos. Neste momento o professor aproveita para explicar o que são as curvas de nível, formas do terreno e feições geomorfológicas características, como colinas, esporões, talvegues etc., e suas diferentes representações gráficas no mapa de georientação.

6. Utilização da bússola para realização de percursos a azimute em direção a referências lineares - após adquirir os conceitos fundamentais anteriormente citados, o georientista está apto a executar atividade individual de navegação com 
bússola. São descritos o funcionamento da bússola e as técnicas de orientação pelos azimutes. Como atividade prática final é aplicada à determinação por azimutes em um espaço aberto (aproximadamente $20 \mathrm{~m}$ x 20m) com vários PCs visíveis. Numa folha de papel é desenhado apenas o percurso a realizar e os meridianos correspondentes em todos os PCs. Antes de iniciar a atividade é exemplificada a forma de realizar a leitura e orientação azimutal.

\section{Percurso para Georientação}

O percurso em equipes foi desenvolvido para a Georientação para que os alunos calouros em Geologia ou Geografia criem espírito coletivo, troquem informações geológicas, discutam no campo tentando encontrar soluções para problemas, desenvolvam o raciocínio geológico e espacial com o incremento do senso de orientação em atividades de campo.

A partida das equipes é realizada em tempos diferentes, sendo que o tempo de realização do percurso para cada equipe é cronometrado. O total de pontos de controle deverá ser igual para todas as equipes. Neste aspecto podem-se elencar as vantagens e desvantagens da sua aplicação:

\section{Vantagens}

- Competição direta entre as equipes;

- Maior acompanhamento do desenrolar da prova;

- A atividade de grupo é mais motivante.

Desvantagens

- A organização é mais complexa.

\section{Aplicação da Georientação}

O trabalho técnico de elaboração de uma atividade de georientação começa desde o mapeamento da região onde serão escolhidos os Pontos de Controle georreferenciados. Cada ponto de controle (afloramento) conterá informações técnicas e científicas que serão utilizadas na confecção dos mapas. Estes, além da caracterização litológica, individualizarão feições geomorfológicas, histórico-culturais, vegetação, declividade, dentre outras, que serão utilizadas como pontos de referência adicionais. Os pontos devem contribuir para localização do georientista e fixação adicional do conhecimento geológico ou geográfico.

Um percurso de georientação é composto por um ponto de partida, um ponto de chegada, que pode ser ou não o mesmo, e uma série de pontos intermediários numerados por onde o georientista deverá passar seguindo, ou não, a seqüência determinada no mapa (modalidade CBO). Estes pontos conterão uma série de informações (rocha, estruturas sedimentares ou tectônicas, geomorfologia, forma do afloramento, árvores, ruínas etc.). É importante que os PCs contenham informações geológico-estruturais (geológicas, geomorfológicas e/ ou estruturais) que possam ser facilmente observadas, medidas, analisadas e até mesmo descritas, neste caso para os alunos do curso de graduação em Geologia, ou informações geomorfológicas, de solo ou uso e ocupação para os alunos do curso de graduação em Geografia.

As informações dos pontos de controle caracterizam (ou não) o próximo ponto, auxiliam ao georientista estabelecer relações entre dados coletados, e se "georientar" no mapa e terreno. Estes PCs deverão conter alguma feição geoestrutural que possa ser medida para confirmar a passagem do aluno no ponto de controle.

Ao encontrar a baliza, o georientista deverá anotar na caderneta de campo a(s) feição(ões) e estrutura(s) observada(s) com sua(s) respectiva(s) medida(s). Esta é a principal diferença na marcação de ponto entre a georientação e a orientação tradicional (na qual o participante comprova apenas com o picotar do cartão de controle), pois a anotação em caderneta com as informações e medidas corretas confirma a passagem do georientista pelo local.

O georientista deverá se preocupar com o tempo de realização do percurso e, na seqüência das pistas geológicas ou geográficas, tais como direção de lineações, mergulho de camadas, feição geomorfológica, dobras, de forma que ele possa completar o percurso e relacionar as diferentes feições geológicas da região estudada.

Nesta nova modalidade de ensino, o praticante deverá abordar conceitos e habilidades cuja aquisição, será fundamental para a realização de atividades práticas e estágios de campo: leitura de feições geológicas e geomorfológicas, localização de afloramento em carta topográfica e conseqüente interpretação geológica.

A aprendizagem da simbologia inserida no mapa e a sua relação com o terreno (Tabela 2) revelam-se importantes para o sucesso na realização de percursos de georientação, uma vez que permite uma fácil localização e orientação no mapa, bem 


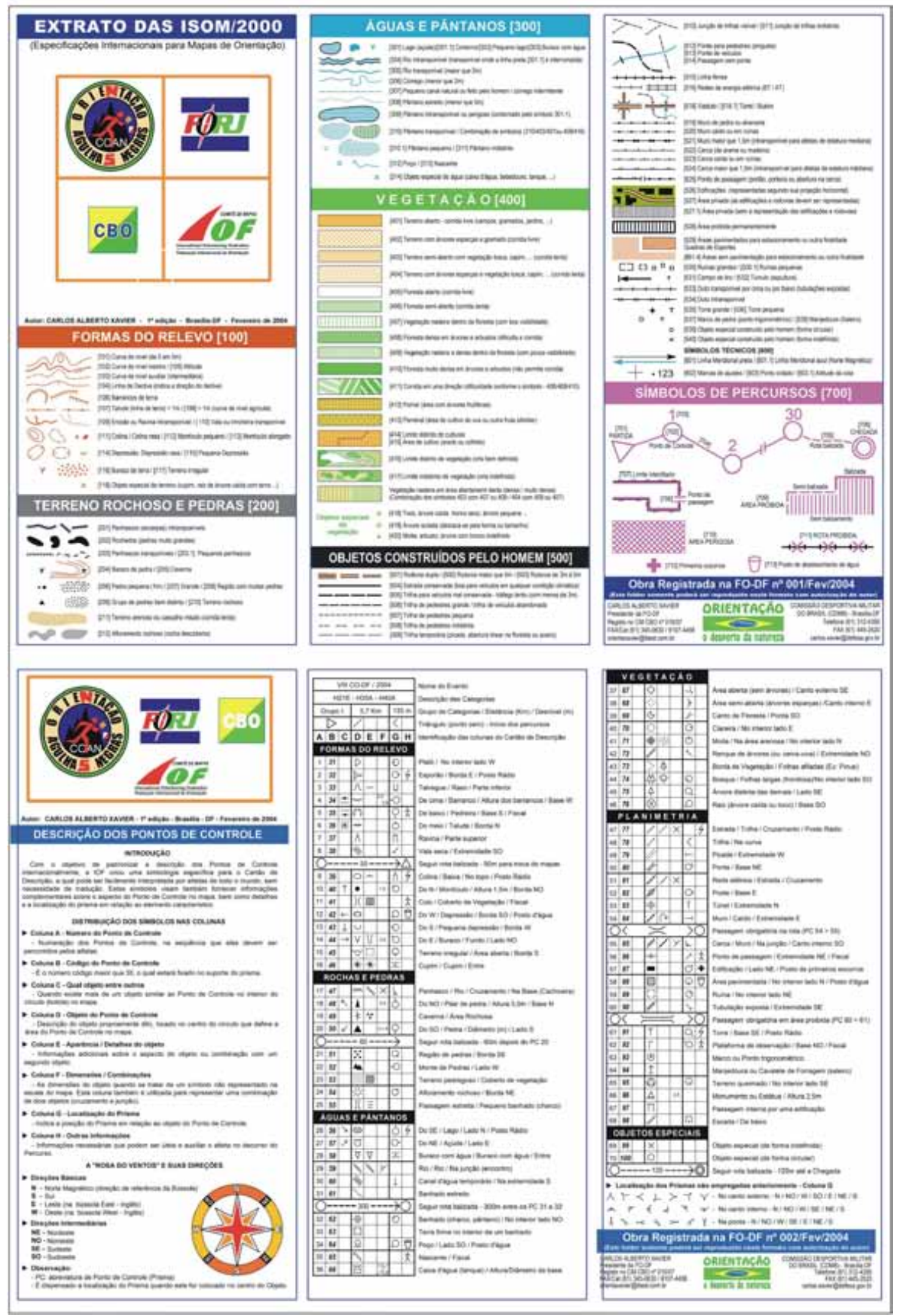

Tabela 2 e 2a. Simbologia do Cartão de Descrição dos pontos. Os elementos estruturais devem ser adicionados à tabela para comporem o quadro geral de símbolos previamente discutidos com os georientistas 


\begin{tabular}{|c|c|c|c|c|c|c|c|c|c|}
\hline$m$ & Dorance & 푤 & Trumenerions & 6 & Compo somite & & 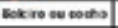 & \pm & Sortint \\
\hline क & Modiats: & $A$ & Buscdenal in & & Clendis & 2 & $R=x$ & II & Aomats \\
\hline$\Rightarrow$ & arpors ds euth & 11 & Eitopretiventis & $\phi$ & tim & 0 & Marcese & 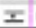 & bensen \\
\hline $\mathrm{D}$ & mis & 0 & 400 & $\theta$ & vive exinaste & 0 & Area do curnibs & $<$ & Conbenan \\
\hline b & Eaperas & $\bar{v}$ & 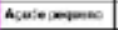 & 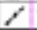 & nera & * & Disn & $\perp$ & Curso anders \\
\hline $5 x$ & Codeth & $\nabla$ & Arated d by & & 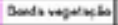 & 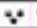 & 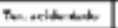 & $\pi$ & 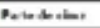 \\
\hline$\Omega$ & Tarwogns & 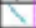 & Clomp & $\mathrm{A}$ & Besaus & II & Conpos:ae. rns & H & menak \\
\hline A & Ftemex & \$ & Camat & 7 & Panquis ierstant & $x$ & Cotdo enesce. & $\pi$ & Solvo \\
\hline$\theta$ & verisen & - & cheres & $\angle$ & teroes & $x$ & 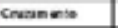 & I & Nebese \\
\hline 0 & Cose & $=$ & 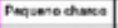 & [] & Disins & $y$ & 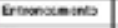 & $\rightarrow$ & man \\
\hline$\cdot$ & morkus & 1 & 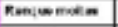 & Q & Puate & - & $N=\infty$ & $x$ & Ento \\
\hline X & cen & D & Tame Serst & $\prime$ & Nuro & $v$ & russ & $\star \Delta$ & $(n+x+5=0)$ \\
\hline 9 & Oowatess & Q & noso & $A$ & Cant & & Atans & 8 & intrescolnis \\
\hline 0 & 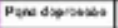 & $\alpha$ & Hervents & $f$ & Dame & 3 & Tam-operemp & $<$ & sum: \\
\hline V & Bureso & 8 & Charce wroth & $T$ & Terr: & $\theta$ & $n: m=0$ & $\theta$ & forto dequs \\
\hline$m$ & Pentanear & $\$$ & Cental Impoing & $A$ & Pvitus & $\hat{Y}$ & $\cos a s$ & 0 & Ponte fivigus \\
\hline$\%$ & 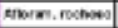 & 맘 & Catarifigua & $\Gamma$ & 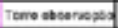 & $I$ & Aenters & 3 & Damorikin \\
\hline$k$ & cmmss & 8 & Cownos atute & $t$ & nefallow & s & 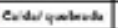 & $\hbar$ & concodeds. \\
\hline$\Delta$ & Pos & - & Cuntar,ate & $\Delta$ & FECASDECEN & 0 & Berse wents & + & 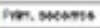 \\
\hline$\overline{8}$ & 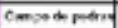 & 0 & 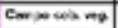 & 5 & Arenrs: & $\overline{7}$ & 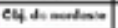 & $x$ & Roo pitidi \\
\hline
\end{tabular}

Tabela 2a.

como facilita a opção pelo trajeto mais correto.

As situações de aprendizagem devem ser organizadas de modo que o aluno adquira os conhecimentos sobre a simbologia topográfica básica do mapa, através da consulta da legenda nele inserida. Sempre que ocorrer uma mudança no tipo de mapa utilizado, devemos fazer uma recapitulação desta fase, chamando atenção para as diferenças existentes na simbologia utilizada em cada mapa.

Quando o aluno tem acesso ao mapa deverá em primeiro lugar perceber o que o espaço representa e indicar no mapa a sua localização. Para tal, o professor (ou georientador) deverá dar indicações sobre os pontos de referência, elementos característicos tais como, feições geomorfológicas, acidentes geográficos, etc, do local em que se encontram e a sua representação no mapa.

Após localizar com precisão o local em que se encontra, o georientista deverá orientar o mapa de acordo com a disposição dos pontos de referência no terreno. O georientador deverá procurar transmitir ao praticante a sensação de estar dentro do mapa, no local indicado.

A noção do espaço percorrido ou a percorrer pelos praticantes durante a realização do percurso, também é importante. Assim o praticante deverá saber relacionar o espaço representado no mapa e a sua correspondência no terreno. As noções dos espaços percorridos desenvolvem-se com a prática e é possível de ser melhorada através da contagem de passos aferidos que dão uma informação sobre o espaço percorrido.

Nas primeiras situações de realização de percursos em espaços mais amplos, onde os praticantes desconhecem o terreno, devemos marcar percursos que garantam o sucesso coletivo. Começamos por marcar percursos em que os pontos de controle são colocados nos locais onde os praticantes devem realizar uma opção sobre o trajeto a realizar, como por exemplo, em todos os cruzamentos de caminhos.

Assim, os praticantes são colocados em situações nas quais o percurso é realizado seguindo elementos característicos significativos (estradas, caminhos, linhas de alta tensão etc.) denominados de corrimão.

\section{Aspectos pedagógicos complementares}

O conhecimento do relevo e feições geológicas com a sua correta leitura no mapa de georientação é importante componente de trabalho de campo quando se efetuam os percursos. Devem ser escolhidos elementos bem característicos, de grande fidelidade, que permitam "navegação" com precisão e trajetos mais apropriados, que requeiram menos esforço por parte dos georientistas.

O treinamento e a aquisição de conhecimentos em três dimensões (3D) são fundamentais para o sucesso na realização de percursos de georientação, e consequentemente na futura atuação profissional em atividades de campo; por vezes, os pontos de controle estarão localizados em acidentes do terreno (reentrâncias, esporões, colinas, depressões etc.).

Os georientistas deverão diferenciar entre vários montes, qual é o mais elevado, a inclinação relativa das suas vertentes etc. Quando decidir sobre o melhor itinerário a percorrer, a noção da estrutura do terreno possibilitará realizar opções de caminhamento mais corretas. Assim, em rápida leitura deverão visualizar as formas principais do terreno, ficando a leitura detalhada restrita às zonas dos Pontos de Controle.

\section{Considerações finais}

O presente trabalho vem estimular e contribuir para a inovação e incentivo ao ensino de atividades de campo na área das Geociências. A georientação pode integrar ideias e soluções para criar novas ferramentas de trabalho que melhorem o aprendizado em Geociências e representa uma forma alternativa e inovadora para o progresso do ensino de Geociências nas universidades brasileiras. A complementação pedagógica auxiliar, para profissionais que atuam na área de educação superior, é um tipo de iniciativa que facilita a incorporação efetiva na melhoria da qualidade de ensino das Geociências, que incrementa a perspectiva de trabalho dos egressos. 
A georientação, como qualquer nova proposta de disciplina, está aberta a críticas tanto por ser uma nova proposta acadêmica, quanto pela necessidade de haver etapas de aperfeiçoamento. Excursões de campo fazem parte da tradição e rotina, não só do ensino das Geociências, mas de tudo que está relacionado à Geologia e Geografia, pois a Terra é o laboratório do geólogo e geógrafo, e o mapa sua representação espacial, ou espelho do seu trabalho. Possivelmente, outros ramos do conhecimento como, por exemplo, as ciências biológicas e florestais, também poderão fazer uso deste trabalho como base para criação de percursos alternativos específicos que auxiliem no melhor desempenho de seus alunos em atividades de campo.

\section{Agradecimentos}

Os autores agradecem os comentários dos revisores deste trabalho, bem como aos colegas do Fórum Nacional dos Cursos de Graduação em Geologia, representado por coordenadores de cursos de graduação e demais professores do ensino superior que agregam interesse especial na atividade de ensino e que buscam incessantemente realizar um trabalho digno, honesto e de qualidade.

\section{Referências Bibliográficas}

Baltazar, J. 1998. Documento de apoio para a formação de professores. URL: <http://www. fpo.pt/manuais/Doc_apoio_profs.doc. > Acesso 16/out/2009.

Carvalho, A.M. 1985. Corrida de Orientação Desporto e Aventura na Natureza. Revista Horizonte, 1 (5), Jan/Fev 1985, pp. 152-155.

Confederação Brasileira de Orientação. 1999. CBO: URL: <http://www.cbo.org.br>. Acesso: 12/ jun/2010.

Friedman, R.M.P. 2003. Fundamentos de Orientação, Cartografia e Navegação Terrestre. 1 ed. Curitiba, Pro Books, 365 p.

Hasselstrand, G. 1987. Learning orienteering step by step. IOF, Sollentuna, Sweden. 157p.

Lopes, O.R. 2005. Teoria e Prática em Geologia: Revisitando o papel dos trabalhos de campo, Rio de Janeiro: DEGEOC/UFRuralRJ. 56p. (Monogr. Trab. Graduação).

Lourtie, A. 1967. La Course d'Orientation: Sport Populaire. Rev. Educ. Phys. 7(4), Dez 1967. URL: <http://www.fpo.pt/manuais/doc_apoio_form pratic/Doc_apoio_form_pratic.html. $>$ Acesso: 16/out/2009.

Mendonça, C. 1987a. Orientação Desporto na Natureza. Coleção Desporto e Sociedade, n¹, DGD, Lisboa, 1987a.URL:<https:// woc.uc.pt/fcdef/clas s/geralsummary. do idclass $=387$ \&idyear $=5>$. Acesso: $16 /$ out/2009.

Mendonça, C. 1987b. Corrida e Orientação na Escola. Revista Horizonte, 3(17):154-159.

Norman B., Yongstron, A. 1991. Orienteering technique from start to finish. Swedish Orienteering Federation, Sweden, 1991. URL: https:// woc.uc.pt/fcdef/class/getbibliography. do idyear $=5 \&$ idclass $=387$. Acesso: $16 / 0 \mathrm{ut} / 2009$

Palmer P., Martland J. 1989. The Coaching Collection. British Orienteering Federation, Derbyshire, GB, $1^{a}$ edição 1989. 200 p.

Porter, S.C.1987. Physical Geology, John Wiley and Sons, Inc.; New York: 750 p.

Renfrew, T., McNeill, C., Palmer, P. 1993. Orienteering for the Young - Guidelines International Orienteering Federation, Sweden: 1993.

Soares, P.C. 2004. O papel do professor e do aluno no projeto pedagógico. Curso de Pós- Graduação em Geologia da UFPR - Depto Geologia. 2004. Arquivo em .doc extraído da página URL: < $\underline{w w}$. geologia.ufpr.br/posgraduacao/pgtextos $>$. Acesso: 5/jun/2008.

Souza, L.B., Nummer, A.R., Marujo, M.P. 2006. Georientação Anais XXXLVIII Congresso Brasileiro de Geologia, Aracajú. Núcleo BahiaSergipe V. 1, p.35.

Teixeira, W., Toledo, M.C.M., Fairchild, T.R., Taioli, F. 2009. Decifrando a Terra. $2^{a}$ ed. $3^{\text {a }}$ reimpr. São Paulo: Cia. Ed. Nacional. Cap. 4, p. 63-82.

Thibon, J.P. 1983. L'Orientation EPS, 181, Mai/Jun 1983, p. 60-63.

URL: <http://inema.com.br/mat/idmat027258. htm >. Acesso: 16/out/2009.

URL: <http://jornalnacional.globo.com/Jornalismo/ JN/0AA1053187-3586-366718,00.html > . Acesso: 13/abr/09.

URL: $<$ http://run.to/orienta $>$. Acesso: 16/out/2009.

URL:<http://www.adventuremag.com.br/dicas/ EpAyVAyuZVqKXUWCVk.php>. Acesso: 15 / out $/ 2009$.

URL: < http://www.forj.com.br/>. Acesso: 21/ out/ 2009.

URL: > > http://www.cbo.org.br/site/desporto\%20 educacional/escolas/histórico $\% 20$ na $\% 20$ escola. pdf> Acesso: 10/04/2009.

URL: < http://www.cbo.org.br/site/institucional/ index.php >. Acesso: 01/jun/2009.

URL: <http: //www.fpo.pt>. Acesso: 23/out/ 2009. 